\title{
Urological resident exposure to transurethral surgical options for BPH management in 2012-2013: A pan-Canadian survey
}

\author{
Tal Ben-Zvi, MD; ${ }^{*}$ Pierre-Alain Hueber, MD; ${ }^{\dagger}$ Roger Valdivieso, MD; ${ }^{\dagger}$ Mounsif Azizi, MD; ${ }^{\dagger}$ Come Tholomier; \\ Marc Bienz;; Naeem Bhojani, MD; Quoc-Dien Trinh, MD, Kevin C. Zorn, MD, FRCSC ${ }^{\dagger}$
}

*Section of Urology, Department of Surgery, Centre Hospitalier de l'Université de Laval, Québec, QC; 'Section of Urology Department of Surgery, Centre Hospitalier de I'Université de Montréal, Montréal, QC; §Faculty of Medicine, McGill University, Montréal, QC; * Division of Urology at Brigham and Women's Hospital and Dana-Farber Cancer Institute, Harvard Medical School Center for Surgery and Public Health, Boston, MA

Cite as: Can Urol Assoc J 2014;8(1-2):54-60. http://dx.doi.org/10.5489/cuaj.1647 Published online February 10, 2014.

\section{Introduction}

Since its first description by McCarty in 1932, transurethral resection of the prostate (TURP) has been the unopposed standard in surgical treatment of benign prostatic hyperplasia (BPH). The most common indication for $\mathrm{BPH}$ surgical treatment is bothersome lower urinary tract symptoms (LUTS) associated with prostatic obstruction refractory to conservative or medical therapy. Since the introduction of pharmacological treatment, the rate of TURP has been in decline. ${ }^{1}$ TURP remains the dominant form of surgery for $\mathrm{BPH}$ in Canada. ${ }^{2}$ The fundamental importance of this surgery explains why the Royal College of Physicians and Surgeons of Canada (RCPSC) ${ }^{3}$ classifies TURP as a "List A" surgical procedure, wherein "the fully trained resident must be competent to individually perform" the procedure.

In recent years many minimally invasive surgical therapies (MIST) for BPH have been developed. Among them holmium laser enucleation of the prostate (HoLEP), GreenLight photoselective vaporization of the prostate (PVP) and the Olympus Plasma Button are being increasingly used in $\mathrm{BPH}$ in the United States (in 2008, TURP accounted for $30 \%$ of all BPH procedures). ${ }^{4}$ In Canada, a similar trend can be observed, characterized by a continuous increase in the use of MISTs albeit at a slower pace; in 2011, TURP still represented more than $90 \%$ of all $\mathrm{BPH}$ procedures in the country. ${ }^{2}$

Most urology residency training programs are based in tertiary care centres and are typically designed to offer exposure to major surgical cases. In this context, and with the increasingly heavy demands of a residency training program, it is possible that BPH surgeries can become relegated as "minor" surgeries with proper exposure lagging behind. However, the reality is that urologists perform fewer major cases, focusing instead on less invasive procedures, such as $\mathrm{BPH}$ surgeries.

Moreover, the advancements in BPH surgical management, including MISTs, raise an educational conundrum for Canadian urological training programs. With TURPs being performed less, are residents sufficiently exposed to attain competency for their future practice? With the emerging MISTs, is there a need, or an advantage, to train future urologists in these novel technologies? If yes, which modalities?

In this context, we evaluate the perceptions of Canadian urology residents on current surgical management of $\mathrm{BPH}$ in their training centres in the 2012-2013 academic year. Furthermore, we assess whether they felt they received sufficient exposure to the various BPH surgeries and whether they felt adequately prepared for their future urological practice. Finally, we capture their opinions on various novel BPH MISTs.

\section{Methods}

Resident polling was conducted via an anonymous bilingual (English/French) online 16-item questionnaire. Links to the questionnaire were sent to the 13 Canadian urological program directors and they were asked to forward them to their residents. Reminder emails were sent out and the survey was available for 8 weeks.

The questionnaire was divided into 4 parts: (1) demographics, (2) surgical options and centre practices, (3) quantification of surgical exposure and (4) qualification of exposure level.

Demographic information included age, sex, resident year and academic centre. Centre information included available transurethral BPH (TUBPH) surgical options, frequency of preoperative prostate gland transrectal ultrasound (TRUS) sizing and length of hospitalization.

Quantification data were collected on observed versus assisted/performed procedures. Qualitative data were col- 
lected on subjective levels of exposure, along with perceived future importance of different BPH surgical modalities. Results were tabulated and analyzed via surveymonkey. com and Excel 2010.

\section{Results}

Overall participation level was $51.74 \%$ varying from $0 \%$ (in $1 / 13$ centres) to $100 \%$ (in $1 / 13$ centres) (Table 1 ). Respondents were $76.7 \%$ male with an average age of 29 .

Residents reported a mode of 11 to $20 \mathrm{TUBPH}$ cases performed/month/centre (Fig. 1a). The average number of TURP cases/month according to resident range from 38 at UBC to 8 at the University of Sherbrooke (Fig. 1b).

Open simple prostatectomies (Millins) are performed at an estimated frequency of 0 to 5 cases/month in all 12 reporting centres (22 respondents report 0-5 cases/month, 1 respondent said "I don't know").

Preoperative TRUS sizing is rarely performed in half of the centres (6/12) and to various degrees in the other half. The mean length of average hospitalization stays for TURP and MISTs were 24.9 hours and 22.3 hours, respectively $(p=0.017)$.

The surgical options available were: monopolar TURP, GreenLight PVP, bipolar TURP and Holmium (holmium laser ablation of the prostate/HoLEP/ holmium laser resection of the prostate) (Table 2). We also tallied their level of exposure to these surgical modalities (Fig. 2).

According to the responses, the most commonly performed MISTs were: GreenLight PVP $(25,43.1 \%)$, Holmium $(7,12.07 \%)$, none $(21,36.2 \%)$, other $(5,8.6 \%$, all reported as TURP). Senior residents (R3-R4-R5) would like additional exposure to GreenLight, bipolar TURP, Olympus PlasmaButton, HoLEP, Thulium and monopolar TURP dur- ing their residency (Fig. 3a). Residents estimated that the following BPH surgical options will be "very important" during their future practice: monopolar TURP, GreenLight and bipolar TURP (Fig. 3b). All of the younger residents (R12) felt they received sufficient exposure to TUBPH surgeries at their training centre (Fig. 4).

\section{Discussion}

The use of TURP to treat LUTS associated to BPH is still the gold standard. ${ }^{5}$ While more challenging surgeries exist and must be mastered during residency, most community urologist spend a significant time performing "minor" surgeries, such as TURP. Therefore, as per the RCPSC, residents are required to be competent to individually perform this breadand-butter procedure. ${ }^{3}$

Resident responses in this survey indicate that the average Canadian academic centre has a mode of 11 to 20 $\mathrm{BPH}$ surgeries performed per month (Fig. 1). TURP exposure increases midway through R3 with more procedures "assisted/performed" than procedures "seen." This is expected with residents passing from their core rotations to full-time urological residents. By $\mathrm{R} 5$, the average resident has seen and assisted/performed in about 50 TURP cases (Fig. 2). Of the 14 responding R5 residents, only 5 had assisted/performed $\geq 50$ cases. Similarly, American residents in R5 in 2004 performed 62 TURPs as opposed to 120 a decade earlier. ${ }^{6}$ This raises the question: at what exposure level is a resident considered competent to individually perform this procedure?

A retrospective study of 4031 TURPs performed by a single surgeon ${ }^{7}$ identified 81 cases required for this single surgeon's skill to plateau in terms of speed (weight of tissue resected compared to operation time). It is unlikely that graduating senior residents should be required to reach their

\begin{tabular}{|c|c|c|c|c|c|c|c|c|}
\hline Participation population & R1 & R2 & R3 & R4 & R5 & Total & No. residents & $\%$ Participation \\
\hline Dalhousie University & 1 & 2 & 2 & 2 & 2 & 9 & 14 & $64 \%$ \\
\hline McGill University & 1 & 1 & 1 & 3 & 3 & 9 & 19 & $47 \%$ \\
\hline University of Ottawa & 5 & 2 & 2 & 1 & 2 & 12 & 17 & $71 \%$ \\
\hline Queen's University & 2 & 0 & 1 & 1 & 0 & 4 & 6 & $67 \%$ \\
\hline University of Toronto & 3 & 1 & 2 & 1 & 1 & 8 & 22 & $36 \%$ \\
\hline McMaster University & 1 & 0 & 1 & 3 & 0 & 5 & 15 & $33 \%$ \\
\hline Western University & 2 & 0 & 1 & 1 & 3 & 7 & 16 & $44 \%$ \\
\hline University of Manitoba & 1 & 3 & 1 & 1 & 3 & 9 & 10 & $90 \%$ \\
\hline University of Alberta & 0 & 0 & 0 & 0 & 0 & 0 & 12 & $0 \%$ \\
\hline University of British Columbia & 1 & 2 & 1 & 1 & 1 & 6 & 15 & $40 \%$ \\
\hline Université Laval & 2 & 0 & 2 & 2 & 2 & 8 & 10 & $80 \%$ \\
\hline Université de Sherbrooke & 2 & 1 & 2 & 0 & 0 & 5 & 5 & $100 \%$ \\
\hline Université de Montréal & 3 & 1 & 1 & 0 & 2 & 7 & 11 & $64 \%$ \\
\hline Total & 24 & 13 & 17 & 16 & 19 & 89 & 172 & \\
\hline No. residents & 35 & 33 & 34 & 36 & 34 & 172 & & Total participation \\
\hline$\%$ Participation & $69 \%$ & $42 \%$ & $50 \%$ & $44 \%$ & $56 \%$ & & & $51.74 \%$ \\
\hline
\end{tabular}




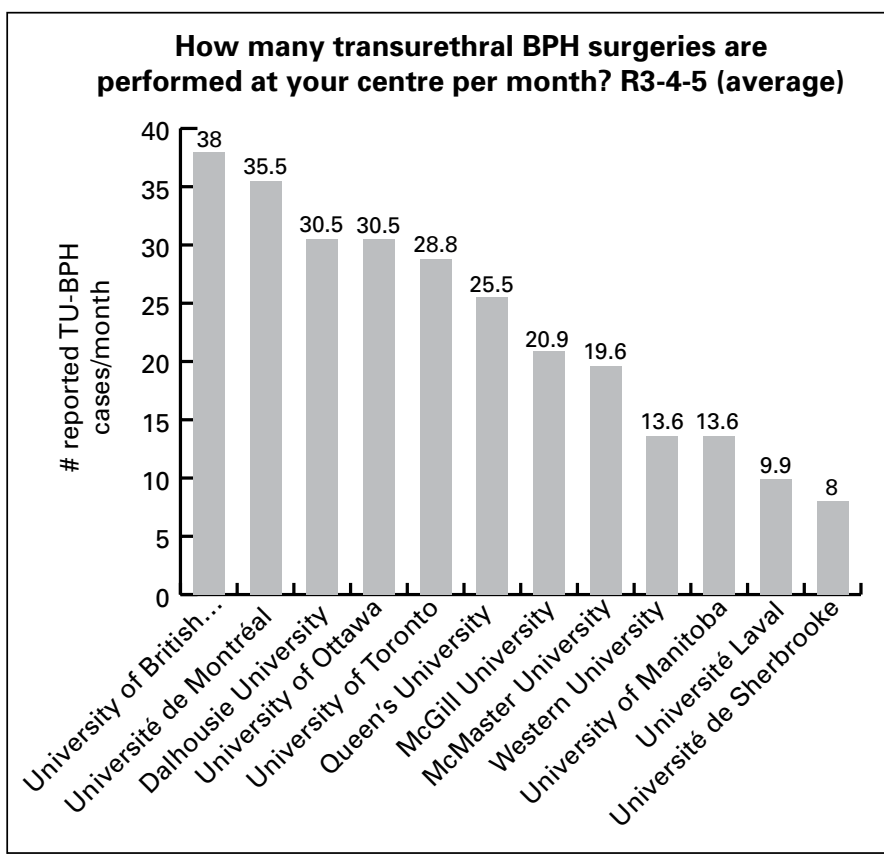

Fig. 1a. How many transurethral BPH surgeries are performed at your centre per month? R3-4-5, based on academic centre. BPH: benign prostatic hyperplasia; TUBPH: transurethral BPH.

speed plateau to be deemed competent to perform these procedures independently. Conversely, the use of a training program involving a virtual reality (VR) simulator could potentially decrease the initial learning curve and surgical complication rate.

To our knowledge, few studies have examined the TURP learning curve. In terms of initial complications, Kalstrom and colleagues evaluated the construct validity of the PelvicVision TURP simulation model. ${ }^{8}$ Eleven medical stu-

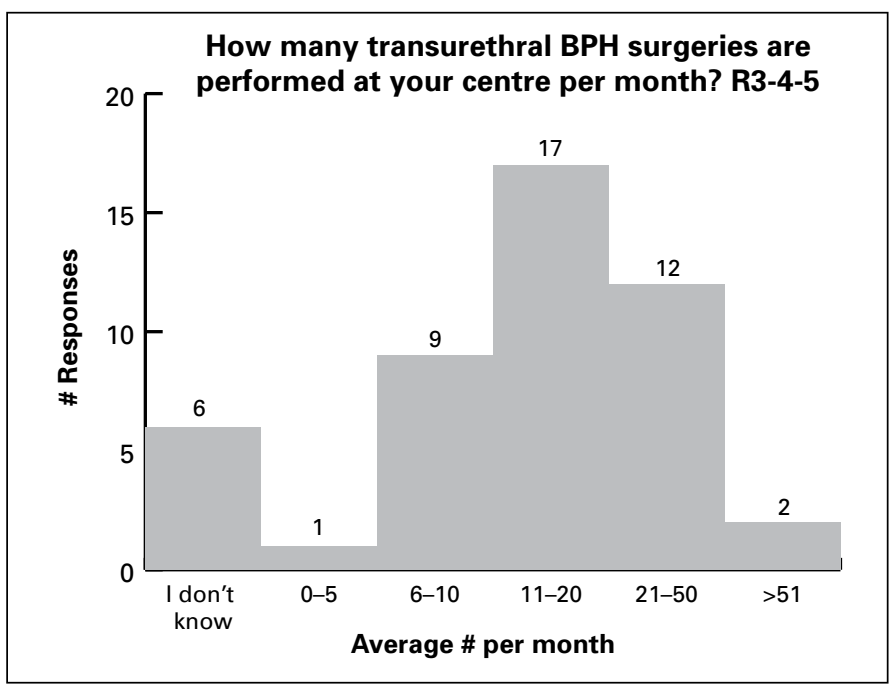

Fig. 1b. How many transurethral BPH surgeries are performed at your centre per month? R3-4-5, based on number of respondents. BPH: benign prostatic hyperplasia.

dents and 9 urologists completed 6 full procedures. Students required double the time with longer resectoscope tip movements, more serious perforations of the prostatic capsule and sphincter, with 5 times higher irrigation fluid uptake/ resected volume. Students demonstrated a positive learning curve, which reduced the complication rate.

Multiple studies have been conducted throughout the development of the University of Washington VR TURP simulator (Medical Education Technologies Inc, Sarasota, FL.6,9-13 These studies demonstrated a strong construct and discriminate validity, realistic blood loss simulation, and improved outcomes with task deconstructions versus full task-training. A similar approach was taken in the development of the

\begin{tabular}{|c|c|c|c|c|c|c|c|c|}
\hline & $\begin{array}{c}\text { Monopolar } \\
\text { TURP }\end{array}$ & $\begin{array}{l}\text { Bipolar } \\
\text { TURP } \\
\end{array}$ & $\begin{array}{c}\text { GreenLight } \\
\text { PVP }\end{array}$ & $\begin{array}{c}\text { Olympus } \\
\text { PlasmaButton } \\
\end{array}$ & $\begin{array}{c}\text { Bipolar plasma } \\
\text { enucleation }\end{array}$ & $\begin{array}{c}\text { HoLAP/ } \\
\text { HoLEP/HoLRP } \\
\end{array}$ & Thulium & $\begin{array}{l}\text { TUMT/ } \\
\text { TUNA } \\
\end{array}$ \\
\hline University of British Columbia & $\checkmark$ & & & & & $\checkmark$ & & \\
\hline Dalhousie University & $\checkmark$ & $\checkmark$ & & & & & & \\
\hline McGill & $\checkmark$ & & $\checkmark$ & & & $\checkmark$ & & \\
\hline University of Ottawa & $\checkmark$ & & $\checkmark$ & & & & & \\
\hline Queens & $\checkmark$ & $\checkmark$ & & & & & & \\
\hline University of Toronto & $\checkmark$ & & & & & & & \\
\hline McMaster & $\checkmark$ & & $\checkmark$ & & & & & \\
\hline University of Western Ontario & $\checkmark$ & $\checkmark$ & $\checkmark$ & & & & & \\
\hline University of Manitoba & $\checkmark$ & $\checkmark$ & & & & & & \\
\hline Université de Laval & $\checkmark$ & & & & & & & \\
\hline Université de Sherbrooke & $\checkmark$ & & & & & & & \\
\hline Université de Montréal & $\checkmark$ & & $\checkmark$ & & & & & \\
\hline Total & 12 & 4 & 5 & 0 & 0 & 2 & 0 & 0 \\
\hline Percentage & $100 \%$ & $33 \%$ & $42 \%$ & $0 \%$ & $0 \%$ & $17 \%$ & $0 \%$ & $0 \%$ \\
\hline
\end{tabular}




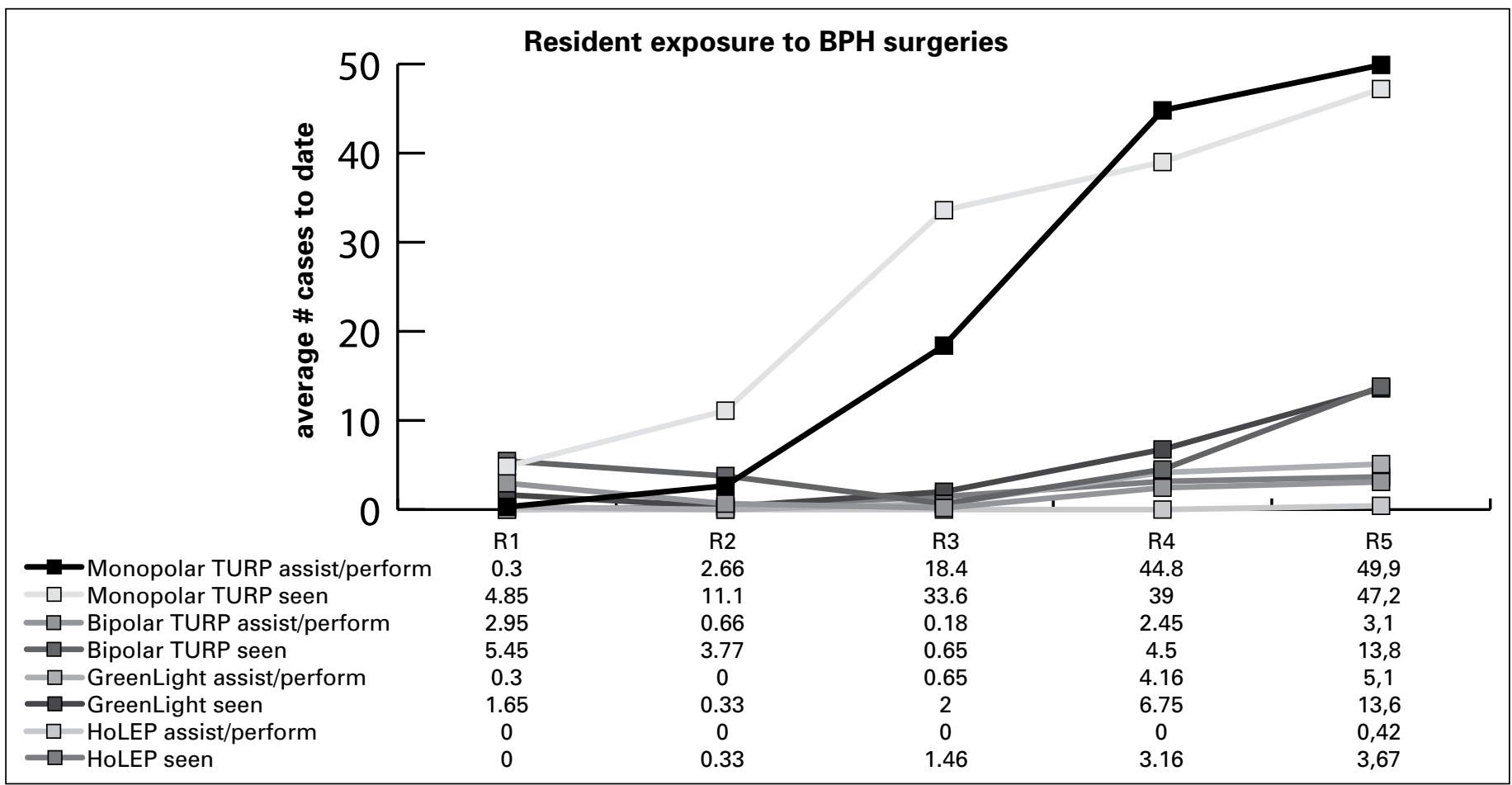

Fig. 2. Resident exposure to BPH surgeries. BPH: benign prostatic hyperplasia; TURP: transurethral resection of the prostate; HoLEP: holmium laser enucleation of the prostate.

GreenLight VR simulator. ${ }^{14}$ This approach includes a VR curriculum using a web-database module, task deconstruc-

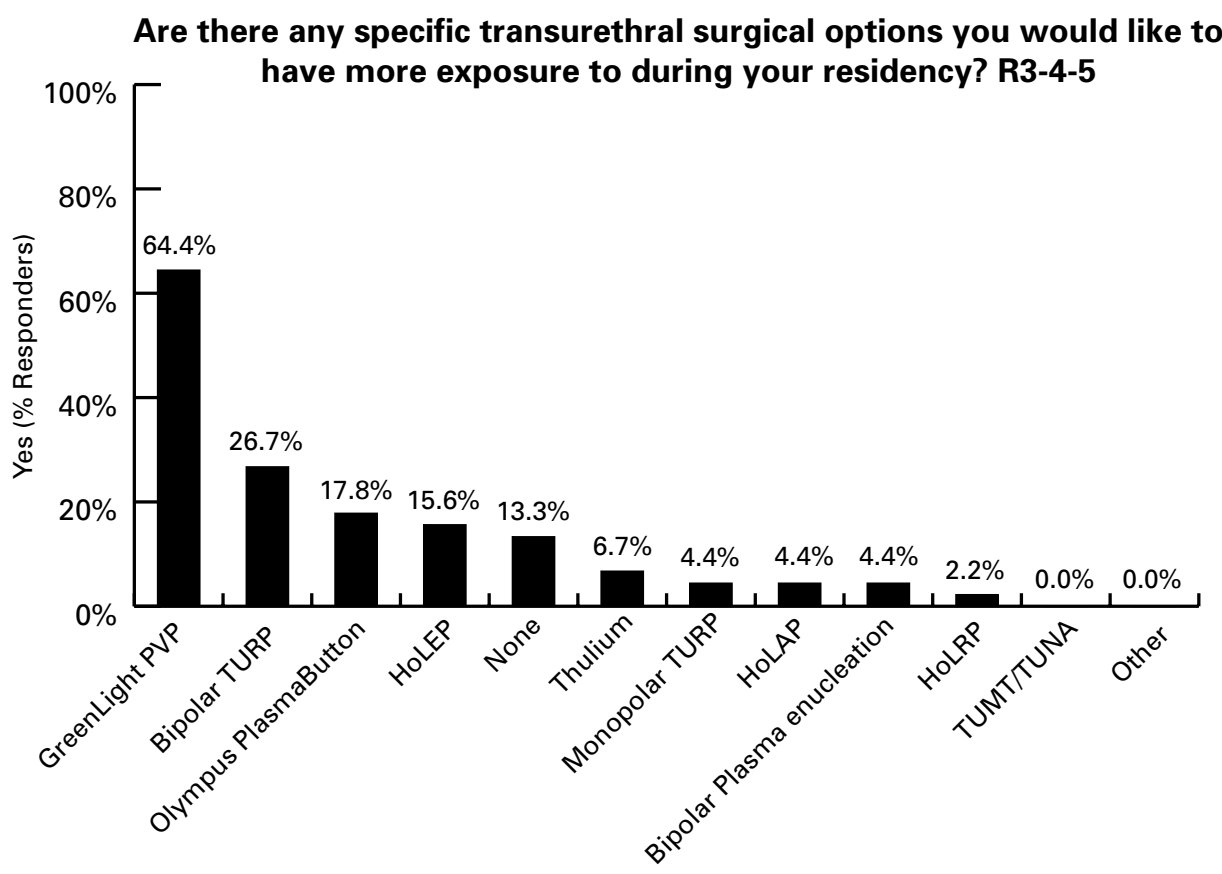

Fig. 3a. Are there any specific transurethral surgical options you would like to have more exposure to during your residency? R3-4-5. TURP: transurethral resection of the prostate; PVP: photoselective vaporization of the prostate; HoLAP: holmium laser ablation of the prostate; HoLEP: holmium laser enucleation of the prostate; HoLRP: holmium laser resection of the prostate; TUMT: transurethral microwave thermotherapy; TUNA: transurethral needle ablation. tions, tutoring mode with intra-case guidance, quizzes and 6 VR training cases. To the authors' knowledge, there are currently 6 GreenLight simulators actively distributed among Canadian centres.

American Medical Systems (Minnetonka, MN) offers a training program for GreenLight certification. It includes case observation, training (e-learning at a training event and/or preceptorship and/or faculty led GreenLight simulator) followed by an initial 10-case experience on well-selected patients. This is followed by ongoing proctorship and mentorship.

In terms of graduating residents, $13 / 15$ (86.6\%) R5s thought they had enough exposure to TUBPH surgeries at their training centre (yes/no questions). While the question was unfortunately not worded to ask if they felt competent to individually perform the procedure, these results would 


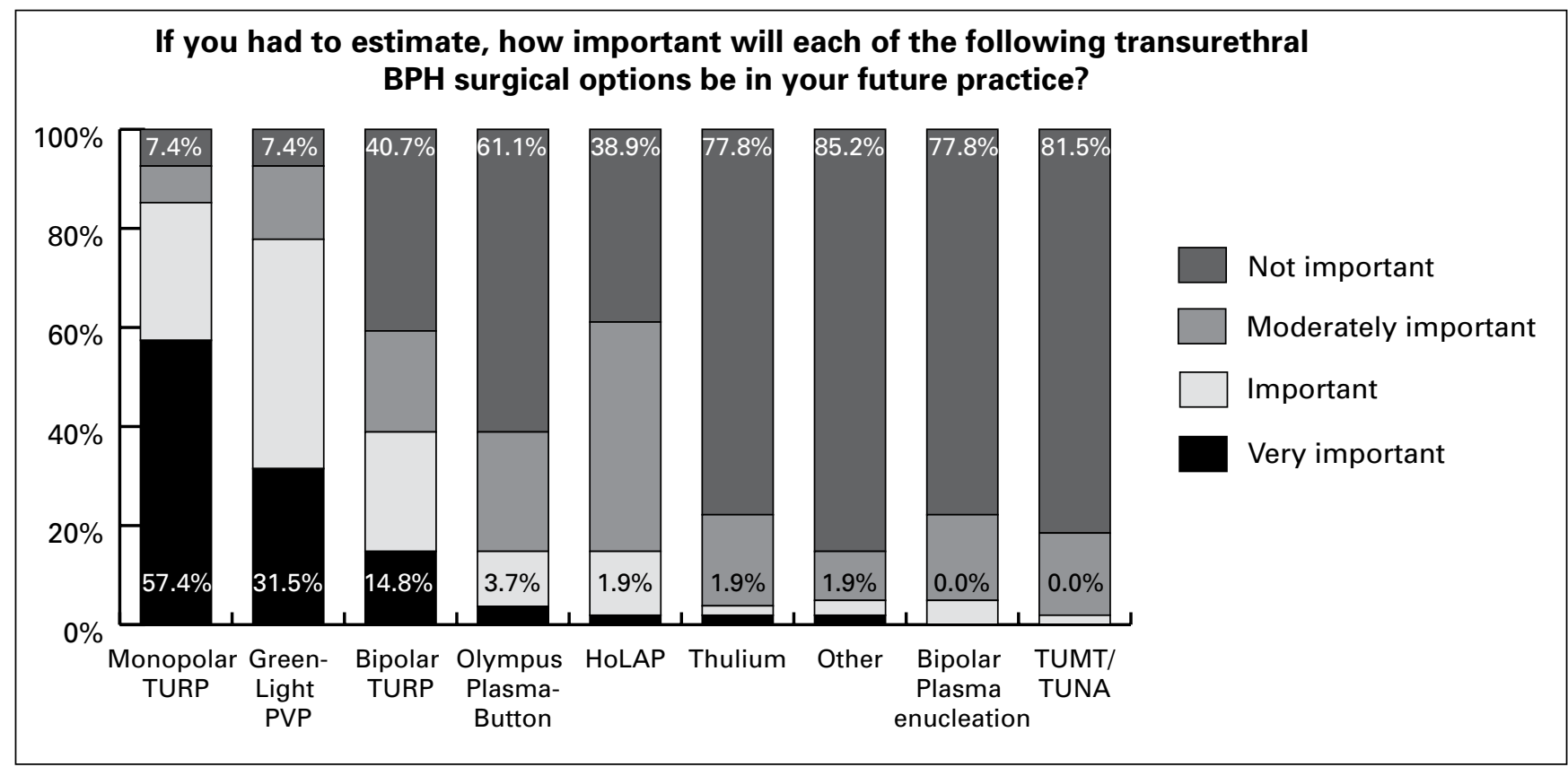

Fig. 3b. If you had to estimate, how important will each of the following transurethral BPH surgical options be in your future practice? TURP: transurethral resection of the prostate; PVP: photoselective vaporization of the prostate; HoLAP: holmium laser ablation of the prostate; HoLEP: holmium laser enucleation of the prostate; HoLRP: holmium laser resection of the prostate; TUMT: transurethral microwave thermotherapy; TUNA: transurethral needle ablation.

indicate that at least the $13 / 15$ yes respondents believed they were. The 2 "no" responses indicated that at their academic site, TURPs were scheduled at the end of the operating day and frequently cancelled, limiting their exposure. Both respondents had assisted/performed 16 to 25 cases (multiple choice answers). The 12 remaining $\mathrm{R} 5$ residents had assisted/ performed 26 to 50 or $>50$ cases. Interestingly, this would suggest that a minimum of 26 cases (but potentially more) are necessary to be able to self-assess "sufficient exposure."
Open simple prostatectomies (Millins) are considered list B surgical procedures, where the fully trained residents should know how to do the procedure, but may not have actually done it alone. ${ }^{3}$ We quantify the frequency of this procedure at tertiary care centres. Due to the construct of the multiple choice answers, we were unable to draw any conclusions. Based on our question ("How many open simple prostatectomies (Millins) are performed at your centre per month?), 22/23 senior residents (R3-R4-R5) reported 0-5

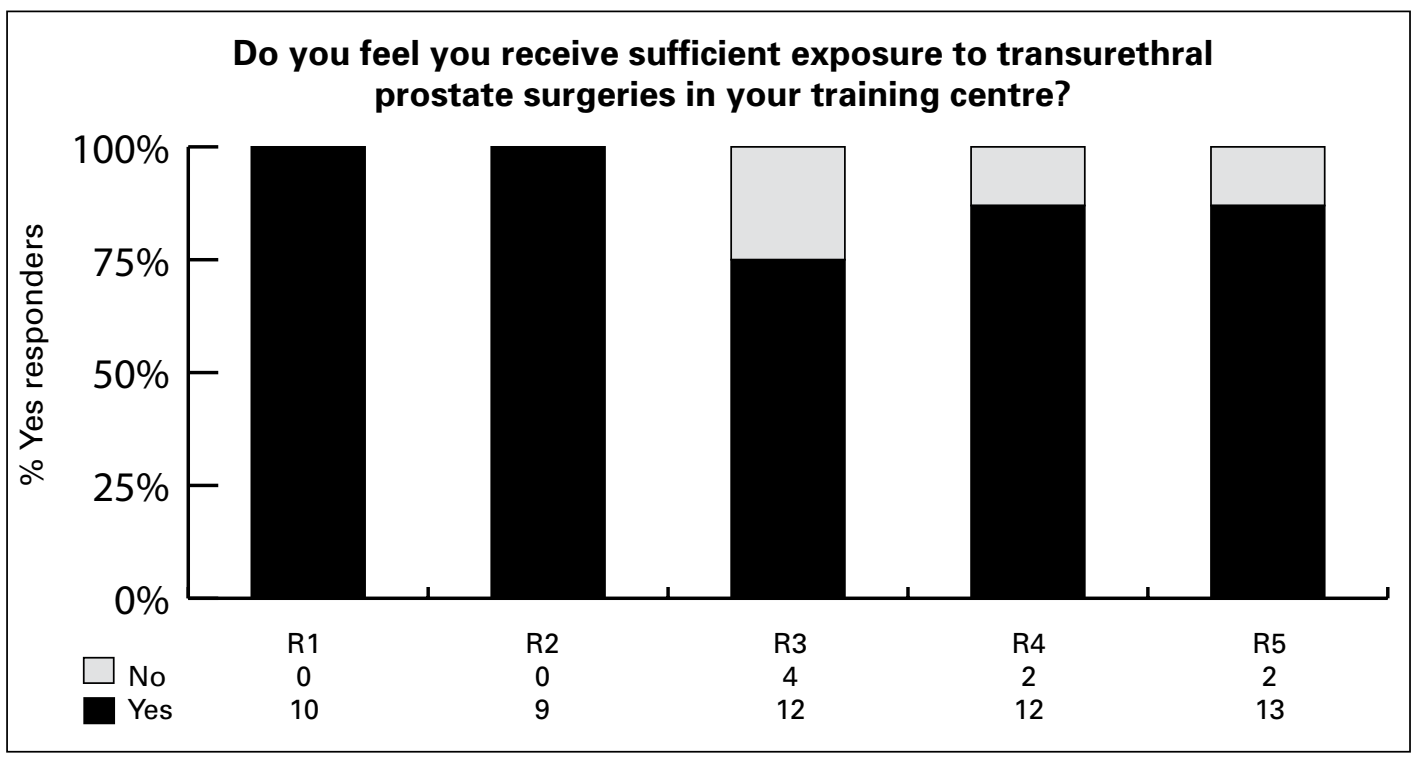

Fig. 4. Do you feel you receive sufficient exposure to transurethral prostate surgeries at your training centre? 
cases/month. In Kingston, Ontario, Izard and Nickel found that only 2 cases of Millins' prostatectomy were performed in 2008, shedding doubt on resident exposure.

CUA guidelines state that open simple prostatectomies remain indicated to treat prostates considered too large for TURP. ${ }^{5}$ Yet it is possible that with the diffusion of laser enucleation techniques, such as HoLEP (with equivalent efficacy and demonstrated superiority particularly in larger glands), the indication for open prostatectomy in $\mathrm{BPH}$ may become more and more limited in the future. ${ }^{15}$ According to the CUA Guidelines, laser prostatectomy, either using potassium titanyl phosphate [KTP] or Holmium:Yttrium aluminium garnet [Ho:YAG], is suitable for most patients, particularly for patients on anticoagulation therapy. ${ }^{5}$ Resident responses reflect current literature; ${ }^{16-18}$ MISTs have shorter hospitalization times compared to TURP. The use of preoperative TRUS sizing is considered a useful tool for surgical planning for TURP ${ }^{19}$ and laser $\mathrm{PVP}^{20}$ and is used to various degrees at 6 of the 12 of responding centres. Currently, preoperative TRUS sizing is not recommended nor suggested in the CUA guidelines as a necessary preoperative assessment for $\mathrm{BPH}$ surgery.

Among all the MISTs, GreenLight PVP is most common used at Canadian academic centres, followed by bipolar TURP and Holmium laser modalities. Bipolar TURP claims advantages over monopolar. Recent meta-analyses ${ }^{21}$ have demonstrated a lower perioperative complication rate, negligible risk of TUR syndrome in small-to-medium sized glands and comparable functional results in comparison to monopolar. However, there is a potentially higher incidence in stricture formation and lack of results on the risk of TUR syndrome with larger glands. Likewise, the Olympus PlasmaButton is attractive due to its minimal learning curve; however, there is limited published data on the thermal tissue penetration and durability. These issues might explain the reticence of Canadian training programs in investing in these technologies.

Residents' desire for additional exposure to each modality is reflected in their judgement of the importance of the different MISTs in their future careers. In the 2012-2013 academic year, GreenLight PVP appears to be the MIST with the most appeal for residents. Desire for additional exposure to GreenLight did not differ significantly between residents in R3-R4-R5 at centres with or without GreenLight $(65.9 \%$ vs. $70.2 \%, p=0.66)$. This opinion may reflect global trends and we can anticipate an increase in GreenLight in Canada. Despite HoLEP currently being the only MIST with level 1 evidence $^{5}$ supporting its use as a first-line surgical option, only $15 \%$ of residents reported wanting more exposure to this technique. This may be explained by the fact that HoLEP is only available in 2 reporting academic centres (McGill and UBC). Whether residents should be trained to competently perform MIST procedures in the future is another question. Perhaps once fundamental endoscopic skills are acquired with TURP, the use of simulators may decrease the exposure needed to acquire competency in these techniques. ${ }^{22}$

This survey has its shortfalls. Participation rates of $51.7 \%$ are hindered by the lack of participation of 1 centre, where 0 responses would indicate that either the survey was never forwarded to the residents or none responded. Additionally, this 16-question survey suffered from a decrease in participation throughout the survey. In trying to make this a user-friendly (and fast) survey, we presented multiple choice options for most questions, inherently reducing the accuracy of our results.

\section{Conclusion}

This survey draws a global picture of the current level of exposure of Canadian urological residents to BPH surgeries. It is reassuring to observe that most senior residents felt they received sufficient exposure to TURP during their training. Finally, the opinions expressed in this survey by the 20122013 residents may give us a preview of the future trends of MISTs in Canada.

Competing interests: Dr. Ben-Zvi, Dr. Hueber, Dr. Valdivieso, Dr. Azzizi, Mr. Tholomier, Mr. Bienz, Dr. Bhojani and Dr. Trinh all declare no competing financial or personal interests. Dr. Zorn is a paid advisor for AMS (Minnetonka, MN).

This paper has been peer-reviewed.

\section{References}

1. Izard J, Nickel JC. Impact of medical therapy on transurethral resection of the prostate: Two decades of change. BJU Int 2011;108:89-93. http://dx.doi.org/10.1111/i.1464-410X.2010.09737.x

2. Hueber $\mathrm{PA}$, Zorn $\mathrm{KC}$. Canadian trend in surgical management of benign prostatic hyperplasia (BPH) and laser therapy from 2007-2008 to 2011-2012. Can Urol Assoc J 2013;7:e582-6. http://dx.doi. org/10.5489/cuaj.203

3. Royal College of Physicians and Surgeons of Canada: Objectives of Training in Urology. http://www. royalcollege.ca/cs/groups/public/documents/document/y2vk/mday/ edisp/tztest3rcpsced002644. pdf. Accessed January 14, 2014.

4. Malaeb BS, Yu X, McBean AM, et al. National trends in surgical therapy for benign prostatic hyperplasia in the United States (2000-2008). Urology 2012;79:1111-6. http://dx.doi.org/10.1016/i. urology.2011.11.084

5. Nickel IC, Méndez-Probst CE, Whelan TF, et al.; and the Canadian Prostate Health Council and the CUA Guidelines Committee. 2010 Update: Guidelines for the management of benign prostatic hyperplasia. Can Urol Assoc J 2010;4:310-6.

6. Sweet RM. Review of trainers for transurethral resection of the prostate skills. J Endourol 2007;21:280-4. http://dx.doi.org/10.1089/end.2007.9979

7. Furuya $S$, Furuya $R, 0$ gura $H$, et al. A study of 4,031 patients of transurethral resection of the prostate performed by one surgeon: Learning curve, surgical results and postoperative complications [in Japanese]. Hinyokika Kiyo 2006;52:609-14.

8. Kallstrom R, Hiertberg H, Svanvik J. Construct validity of a full procedure, virtual reality, real-time, simulation model for training in transurethral resection of the prostate. J Endourol 2010;24:109-15. http:// dx.doi.org/10.1089/end.2009.0114 
Ben-Zvi et al.

9. Kishore TA, Beddingfield R, Holden T, et al. Task deconstruction facilitates acquisition of transurethral resection of prostate skills on a virtual reality trainer. J Endourol 2009;23:665-8. http://dx.doi. org/10.1089/end.2008.0531

10. Rashid HH, Kowalewski T, Oppenheimer $\mathrm{P}$, et al. The virtual reality transurethral prostatic resection trainer: Evaluation of discriminate validity. J Urol 2007;177:2283-6. http://dx.doi.org/10.1016/i. juro.2007.01.120

11. Sweet R, Kowalewski T, Oppenheimer P, et al. Face, content and construct validity of the University of Washington virtual reality transurethral prostate resection trainer. J Urol 2004;172:1953-7. http:// dx.doi.org/10.1097/01.ju.0000141298.06350.4c

12. Sweet $R$, Porter J, Oppenheimer $P$, et al. Simulation of bleeding in endoscopic procedures using virtual reality. J Endourol 2002;16:451-5. http://dx.doi.org/10.1089/089277902760367395

13. Oppenheimer $\mathrm{P}$, Gupta $\mathrm{A}$, Weghorst $\mathrm{S}$, et al. The representation of blood flow in endourologic surgical simulations. Stud Health Technol Inform 2001;81:365-71.

14. Shen Y, Konchada V, Zhang N, et al. Laser surgery simulation plafform: Toward full-procedure training and rehearsal for benign prostatic hyperplasia (BPH) therapy. Stud Health Technol Inform 2011;163:574-80.

15. Gilling PJ. Laser enucleation is increasingly becoming the standard of care for treatment of benign prostatic hyperplasia of all sizes. Eur Urol 2013;63:868-9; discussion 870-1. http://dx.doi.org/10.1016/j. eururo.2013.01.001

16. Al-Ansari A, Younes N, Sampige VP, et al. Greenlight HPS 120-W laser vaporization versus transurethral resection of the prostate for treatment of benign prostatic hyperplasia: A randomized clinical trial with midterm follow-up. Eur Urol 2010;58:349-55. http://dx.doi.org/10.1016/i.eururo.2010.05.026

17. Geavlete B, Stanescu F, lacoboaie C, et al. Bipolar plasma enucleation of the prostate vs open prostatectomy in large benign prostatic hyperplasia cases: A medium term, prospective, randomized comparison. BJU Int 2013;111:793-803. http://dx.doi.org/10.1111/i.1464-410X.2012.11730.x
18. Thangasamy IA, Chalasani V, Bachmann A, et al. Photoselective vaporisation of the prostate using 80-W and 120-W laser versus transurethral resection of the prostate for benign prostatic hyperplasia: A systematic review with meta-analysis from 2002 to 2012. Eur Urol 2012;62:315-23. http://dx.doi. org/10.1016/i.eururo.2012.04.051

19. Reich 0 , Gratzke C, Bachmann A, et al. Morbidity, mortality and early outcome of transurethral resection of the prostate: A prospective multicenter evaluation of 10,654 patients. J Urol 2008; 180:246-9. http:// dx.doi.org/10.1016/i.juro.2008.03.058

20. Hueber PA. Liberman D, Ben-Zvi T, et al. $180 \mathrm{~W}$ vs $120 \mathrm{~W}$ lithium triborate photoselective vaporization of the prostate for benign prostatic hyperplasia: A global, multi-center comparative analysis of peri-operative treatment parameters. Urology 2013;82:1108-13. http://dx.doi.org/10.1016/i.urology.2013.03.059. Epub 2013 0ct 25. 013

21. Ahyai SA, Gilling P, Kaplan SA, et al. Meta-analysis of functional outcomes and complications following transurethral procedures for lower urinary tract symptoms resulting from benign prostatic enlargement. Eur Urol 2010;58:384-97. http://dx.doi.org/10.1016/i.eururo.2010.06.005

22. Herlemann $A$, Strittmatter $F$, Buchner $A$, et al. Virtual reality systems in urologic surgery: An evaluation of the Greenlight simulator. Eur Urol 2013;64:687-8. http://dx.doi.org/10.1016/i.eururo.2013.06.008

Correspondence: Dr. Kevin C. Zorn, 235 Rene Levesque Est, Suite 301, Montreal, QC H2X 1N8; fax: 514-861-3021; zorn.chumurology@gmail.com 